This item was submitted to Loughborough's Research Repository by the author.

Items in Figshare are protected by copyright, with all rights reserved, unless otherwise indicated.

\title{
In vitro calcification studies on bioprosthetic and decellularized heart valves under quasi-physiological flow conditions
}

\section{PLEASE CITE THE PUBLISHED VERSION}

https://doi.org/10.1007/s42242-020-00110-7

\section{PUBLISHER}

Springer Science and Business Media LLC

\section{VERSION}

AM (Accepted Manuscript)

\section{PUBLISHER STATEMENT}

This is a post-peer-review, pre-copyedit version of an article published in Bio-Design and Manufacturing. The final authenticated version is available online at: https://doi.org/10.1007/s42242-020-00110-7.

\section{LICENCE}

CC BY-NC-ND 4.0

\section{REPOSITORY RECORD}

D’Alessandro, Cristian C, Andreas Dimopoulos, Sofia Andriopoulou, Gerasimos AT Messaris, Sotiris Korossis, Petros Koutsoukos, and Dimosthenis Mavrilas. 2020. "In Vitro Calcification Studies on Bioprosthetic and Decellularized Heart Valves Under Quasi-physiological Flow Conditions”. Loughborough University. https://hdl.handle.net/2134/13623839.v1. 


\title{
In vitro calcification studies on bioprosthetic and decellularized heart valves under quasi physiological flow conditions
}

\author{
Cristian C. D'Alessandro ${ }^{1}$, Andreas Dimopoulos ${ }^{1}$, Sofia Andriopoulou ${ }^{2}$, Gerasimos A. T. Messaris ${ }^{3}$, \\ Sotirios Korossis ${ }^{2,4}$, Petros Koutsoukos ${ }^{5}$ \& Dimosthenis Mavrilas ${ }^{1^{*}}$ \\ ${ }^{1}$ Laboratory of Biomechanics and Biomedical Engineering, Department of Mechanical Engineering \& Aeronautics, University \\ of Patras, Greece \\ 2Department of Cardiothoracic, Transplantation and Vascular Surgery, Hannover Medical School, Germany \\ ${ }^{3}$ Department of Medical Physics, University Hospital of Patras, Greece \\ ${ }^{4}$ Wolfson School of Mechanical, Electrical and Manufacturing Engineering, Loughborough University, United Kingdom \\ ${ }^{5}$ Department of Chemical Engineering and FORTH-Institute of Chemical Engineering Sciences, University of Patras, Greece \\ *Corresponding author: Prof. Dimosthenis Mavrilas. \\ E-mail: dmauril@upatras.gr
}

\begin{abstract}
The lifespan of biological heart valve prostheses available in the market is limited due to structural alterations caused by calcium phosphate deposits formed from blood plasma in contact with the tissues. The objective of this work is to present a comparative methodology for the investigation of the formation of calcium phosphate deposits on bioprosthetic and tissue-engineered scaffolds in vitro and the influence of mechanical forces on tissue mineralization. Based on earlier investigations on biological mineralization at constant supersaturation, a circulatory loop simulating dynamic blood flow and physiological pressure conditions was developed. The system was appropriately adapted to evaluate the calcification potential of decellularized (DCV) and glutaraldehyde-fixed (GAV) porcine aortic valves. Results indicated that DCV calcified at higher, statistically non-significant, rates in comparison with GAV. This difference was attributed to the tissue surface modifications and cell debris leftovers from the decellularization process. Morphological analysis of the solids deposited after $20 \mathrm{~h}$ by Scanning Electron Microscopy (SEM) in combination with chemical microanalysis electron dispersive spectroscopy (EDS) identified the solid formed as octacalcium phosphate $\left(\mathrm{Ca}_{8}\left(\mathrm{PO}_{4}\right)_{6} \mathrm{H}_{2} \cdot 5 \mathrm{H}_{2} \mathrm{O}\right.$, OCP). OCP crystallites were preferentially deposited in high mechanical stress areas of the test tissues. Moreover, GAV tissues developed a significant transvalvular pressure gradient increase past $36 \mathrm{~h}$ with a calcium deposition distribution similar to the one found in explanted prostheses. In conclusion, the presented in vitro circulatory model serves as a valuable pre-screening methodology for the investigation of the calcification process of bioprosthetic and tissue-engineered valves under physiological mechanical load.
\end{abstract}

\section{Keywords}

Reactors, Calcification, Constant Composition Reactor, Heart Valve, In Vitro, Mechanical Load, Tissue Engineering

\section{Introduction}

Calcific aortic valve disease is a common disorder accounting for $45 \%$ of deaths from heart valve diseases in USA, occurring in $2 \%$ to $4 \%$ of adults over 65 years old, with an increasing tendency for the elderly [1]. The only possible treatment for end-stage valvular heart disease is a total valve replacement with either mechanical or bioprosthetic valves [2,3]. Differently to mechanical valves, biological implants can adapt to changes in the surrounding tissues and provide a physiological flow pattern that could reduce the risk of thrombosis and plaque formation $[4,5]$. However, to prevent adverse immunological reactions and structural degradation of biological valves, chemical fixation is necessary. This process often involves glutaraldehyde, which enhances structural stability by crosslinking collagen fibers. However, this treatment prevents the active natural remodeling of the tissue by contributing to the deposition of calcium phosphate on the bioprosthetic valve tissue [6]. The formation of mineral deposits, also known as calcification, progressively increases heart valve stiffness and reduces leaflet 
flexibility, eventually leading to the degenerative failure of the implant $[7,8]$. As a result of calcification, bioprosthetic valves have an average lifespan of the implant from 15 to 20 years [6]. In recent years, decellularized valves have shown encouraging results in both short and mid-term viability studies, as they have the potential to grow and adapt to the surrounding tissue while reducing the immunological response [9] Because of the novelty of these implants, there is a lack of comprehensive post-implantation calcification studies. Therefore, the calcification of heart valves needs complete understanding to devise new strategies to monitor and prevent it timely.

Calcific deposits on aortic valves form due to the contact of the respective tissues with blood serum. From a thermodynamic point of view, blood serum is supersaturated with respect to a number of calcium phosphate mineral salts [10]. From all the calcium phosphate phases that could be formed in vivo, octacalcium phosphate $\left(\mathrm{Ca}_{8} \mathrm{H}_{2}\left(\mathrm{PO}_{4}\right)_{6} \cdot 5 \mathrm{H}_{2} \mathrm{O}, \mathrm{OCP}\right)$ is the predominant mineral phase found in explanted valvular prostheses. OCP is a transient (metastable) calcium phosphate phase, formed initially in highly supersaturated media. OCP hydrolyzes eventually to the thermodynamically most stable calcium phosphate phase, hydroxyapatite $\left(\mathrm{Ca}_{10}\left(\mathrm{PO}_{4}\right)_{6}(\mathrm{OH})_{2}\right.$, HAP $)$ accompanied by proton release [11]. Calcification initiates with the formation of primary nuclei at the interface between blood serum and the tissue. Once a critical size is attained, nuclei may grow further, forming macroscopic crystallites. The first crystallites serve as the main calcification sites, enhancing the growth of the calcium phosphate deposits [10]. In addition to thermodynamics, the onset of mineralization depends on biological factors, as well as mechanical and shear forces [12-14].

Mechanical load plays a significant role in the calcification of heart valves. The fatigue damage of fibers, resulting from mechanical stress, may provide the necessary active sites for the nucleation and subsequent growth of the calcium phosphate crystals [11]. In agreement with this hypothesis, heart valve calcification has shown a preference for areas subject to high mechanical deformations and flow stagnation $[4,8,15]$. During ventricular ejection, the annular joints and free edges of the leaflets suffer the highest mechanical load. The ejected blood mass produces the flexion of the leaflets, while stagnation and recirculation of blood take place at the sinuses of Valsalva.

In vitro models play a crucial role in further increasing the understanding of heart valve calcification. These models could serve as a pre-screening platform to identify potential biomaterials before beginning in vivo studies. Given the crucial role of mechanical and chemical factors in the calcification process, in vitro models should replicate, as closely as possible, in vivo chemical and mechanical conditions. Dynamic in vitro circulatory models have been developed to simulate, as accurately as possible, the mechanical parameters affecting the function of heart valves in vivo. Current literature dynamic calcification models acknowledge the importance of maintaining the solution parameters, but they fail to verify or maintain the constancy of conditions as a function of time. Reported studies on dynamic models were based on accelerated fatigue devices that exacerbate the mechanical effects on the valve tissues, enhancing the rates of calcification [1619]. At these conditions, the calcifying solution may become unstable with respect to phase separation. The calcification solution used in most literature reports was not stable. Refreshment of the calcifying solution was done at intervals of days, affecting the constancy of the solution composition, $\mathrm{pH}$ stability, and supersaturation with respect to a mineral phase. Therefore, many calcification investigations neglect the effect and interaction of chemical speciation and buffer systems during crystallization of the mineral deposits $[16,17,19]$.

In the present work, an in vitro calcification system was developed, in which pulsed flow, physiological pressure conditions, and the stability of solution parameters were simulated. This system, capable of rapid screening of prospective biomaterials for heart valve replacement, combines the use of a dynamic circulatory circuit with a well-characterized chemical environment, allowing for accurate real-time monitoring of the calcification process. Calcium phosphate salts may selectively form, on solid surfaces introduced in the fluid medium, through heterogeneous nucleation [20]. The experimental model developed in the present work is based on the working principle of a constant supersaturation reactor (CSR), modified to replicate the in vivo flow and mechanical load [11]. Therefore, unlike literature models, the present system enables accurate control of chemical speciation and the mineralization driving force, i.e., supersaturation. This novelty allows the system to be adapted to monitor the calcification process on different substrates and fluid conditions, thereby providing a unique tool for evaluating biomaterials based on the measurement of kinetic parameters of calcium phosphates formation. The model developed was used to compare the calcification rates of decellularized (DCV) and glutaraldehyde-fixed (GAV) porcine aortic roots. Additionally, the location and the crystal identity of the deposits were investigated with clinical X-Ray mammography and scanning electron microscopy equipped with an electron microanalysis probe (SEMEDS). Furthermore, the pressure gradient changes during mineralization of GAV were investigated and compared at fixed time intervals.

\section{Materials and methods}

The core of the experimental setup was a tailored automated circulatory loop simulating the in vivo systemic circulatory system conditions experienced by aortic valves. Flow, pressure, temperature, and $\mathrm{pH}$ transducers acquired real-time data during experiments. 


\section{A. Kinetics measurements and calcification rates}

In the present work, the mineralization process was considered to proceed through the formation of the relatively unstable OCP phase. OCP was previously identified in mineralized tissues, including heart valves $[7,21]$. The calcification process was driven by the calcium phosphate supersaturation, measured by the respective ratio $(\Omega)$, which quantified the deviation of the solution from equilibrium. The supersaturation ratio, with respect to OCP, was defined as the ratio of ion activity product over the respective thermodynamic solubility product, as shown in (1).

$$
\Omega_{O C P}=\frac{\left(\alpha_{C a^{2+}}\right)^{8}\left(\alpha_{P_{4}^{3-}}\right)^{6}\left(\alpha_{H^{+}}\right)^{2}}{K_{S, O C P}^{0}}
$$

Parentheses denote activities of the respective ions, while exponents denote the stoichiometry of the solution, and $K_{S}^{0}$ denotes the thermodynamic solubility product of the OCP mineral phase.

The formation of the mineral phase is determined by the change in Gibbs free energy and depends on the supersaturation ratio, as seen in (2)

$$
\Delta \mathrm{G}_{O C P}=-\frac{R T}{16} \ln \Omega_{O C P}
$$

$R$ is the gas constant, and $T$ the absolute temperature. During the formation of calcium phosphate crystals, protons are released through the formation of OCP, according to reaction (3). The release of protons was monitored with a $\mathrm{pH}$ electrode and was proportional to the rate of calcification [18]. According to equation (3), the rate of OCP precipitation is proportional to the proton release rate. Neutralization of the released protons, through titration with sodium hydroxide solution $(\mathrm{NaOH})$ of known concentration, could then be used to estimate the precipitation rates. $\mathrm{pH}$ drop as low as 0.005 units triggered the infusion of $\mathrm{NaOH}$ to compensate for the $\mathrm{pH}$ change. The rate of $\mathrm{NaOH}$ addition was used to calculate the extent of the calcification process in vitro, allowing the comparison of different implant cohorts in the same system [10].

\section{B. Experimental conditions}

In order to demonstrate that the test substrates were the sole reason for nucleation and growth of OCP, it was necessary to prove that the test supersaturated solutions were stable over time (i.e., no nucleation phenomena took place in these solutions past relatively long periods). The stability of the supersaturated calcification fluid $\left(\Omega_{O C P}>1\right)$ was verified experimentally to attain the highest possible supersaturation of the test solution. The stability of the solution confirmed a lack of uncontrollable nucleation effects that could take place due to turbulent or higher flow rates, which have been reported to induce spontaneous precipitation [22, 23].

Calcium chloride $\left(\mathrm{CaCl}_{2}\right)$, sodium hydrogen phosphate $\left(\mathrm{Na}_{2} \mathrm{HPO}_{4}\right)$, and sodium chloride $(\mathrm{NaCl})$ were used to prepare the supersaturated calcification solutions. All solutions were prepared from their respective crystalline solids (Merck, USA, or Applichem, GmbH) using ultrapure grade water and filtered through membrane filters $(0.22 \mu \mathrm{m}$, Millipore $) . \mathrm{CaCl}_{2}$ concentration was maintained at $1.4 \mathrm{mM}$, while phosphate levels were calculated based on a $\mathrm{Ca}^{2+}: \mathrm{PO}_{4}{ }^{3-}$ ratio of 1.33 , corresponding to the stoichiometry of OCP mineral phase.

The necessary free ions activities were calculated, taking into consideration all appropriate equilibria, charge, and mass balances, using PHREEQC software [24]. The supersaturation values of the solutions in the present work with respect to OCP were equal to 0.08 .

$\mathrm{CaCl}_{2}$ solutions were standardized by Atomic Absorption Spectroscopy (AAS; Perkin Elmer, AAnalyst 300) and EDTA titrations. $\mathrm{Na}_{2} \mathrm{HPO}_{4}$ solutions were standardized spectrophotometrically (Perkin Elmer Lambda 35), and by potentiometric titrations. The ionic strength was adjusted to $0.15 \mathrm{M}$ by $\mathrm{NaCl}$ addition equal to blood plasma values [25]. The $\mathrm{pH}$ of the mineralization solution was adjusted to 7.4 by the slow addition of standard hydrochloric acid $(\mathrm{HCl})$ or $\mathrm{NaOH}$ (Merck, Titrisol) as required. Mineralization solutions were prepared in the reactor, and water vapor saturated $\mathrm{N}_{2}$ was bubbled through for at least one hour before the start of the experiment, precluding $\mathrm{CO}_{2}$ intrusion during the calcification process. The solutions $\mathrm{pH}$ was monitored using an epoxy body $\mathrm{pH}$ electrode (Cole Parmer, USA) standardized before and after each experiment with NBS standard buffer solutions pH 4.008, 7.413, and 9.180 (Honeywell, Fluka). The entire system was enclosed in an air convection chamber, maintaining the temperature conditions of the circulating aqueous supersaturated solution at $37^{\circ} \mathrm{C}$.

A total of $1750 \mathrm{ml}$ of solution were prepared and introduced into the reactor. The calcium-phosphorus ratio was maintained according to the stoichiometry of OCP, by mixing $\mathrm{CaCl}_{2}, \mathrm{Na}_{2} \mathrm{HPO}_{4}$, and $\mathrm{NaCl}$ at the appropriate concentrations. During the experiments, $\mathrm{pH}$ was maintained at $7.400 \pm 0.005$ by the addition of $\mathrm{NaOH}$ using a $\mathrm{pH}$ feedback-controlled syringe pump (New Era, USA). Ultrasonic flow rate measurements were done throughout the experiment (emTec, Germany) along with pressure, $\mathrm{pH}, \mathrm{NaOH}$ volume

$$
\begin{gathered}
\mathrm{Ca}^{2+}(\mathrm{aq})+x \mathrm{H}_{3} \mathrm{PO}_{4}(\mathrm{aq})+y \mathrm{H}_{2} \mathrm{PO}_{4}{ }^{2-}(\mathrm{aq})+z \mathrm{HPO}_{4}{ }^{2-}(\mathrm{aq})+u \mathrm{PO}_{4}{ }^{3-}(\mathrm{aq}) \\
\rightarrow \mathrm{Ca}_{4}\left(\mathrm{PO}_{4}\right)_{3} \mathrm{H} \cdot 2.5 \mathrm{H}_{2} \mathrm{O}(\mathrm{OCP}, \mathrm{s})+w \mathrm{H}^{+}(\mathrm{aq}) \\
\text { Where } w=3 x+2 y+z
\end{gathered}
$$


added, and temperature measurements. The pressure was monitored using a multichannel interface (AD Instruments, UK), while the rest of the parameters were acquired with a data acquisition unit (U6; Labjack, USA). The obtained data were processed in real-time, using the appropriate software explicitly designed for the system in C\# language (Visual Studio; Microsoft, USA). Experiments were limited to $20 \mathrm{~h}$ of continuous, pulsed flow with physiological pressure levels and moderate flow. Flow rates were set to $2 \mathrm{~L} / \mathrm{min}$ at 60 BPM (beats per minute) and pressure to $80 / 120 \mathrm{mmHg}$ for diastolic and systolic values. Cardiac frequency and pressure were selected, assuming resting hemodynamic conditions. The flow rate was restricted compared to normal hemodynamic conditions $(5 \mathrm{~L} / \mathrm{min})$ to prevent undesirable and uncontrolled nucleation that could affect the solution specificity and stability [22, 23]. Samples were withdrawn at suitable time intervals in each experiment to ensure constant levels of calcium and phosphate in the solution. Calcium concentration in the withdrawn samples was measured by AAS, while phosphorus concentration was measured by UV Visible spectrophotometry. Identification and characterization of the deposits on the tissues were made by SEM-EDS

\section{Design \& Development of the circulatory loop}

The developed system was based on a springless camshaft mechanism. The shape of the cam dictated the linear movement of a cylindrical metallic bellow connected to a hydraulic distributor. The bellow had an effective surface area of $97.65 \mathrm{~cm}^{2}$ and compressed 60 $\mathrm{mm}$ to produce the ventricular ejection. The total stroke volume was adjusted by the addition or subtraction of air from the hydraulic distributor. The cardiac frequency was controlled by regulating the speed of the motor with a pulse width modulation DC motor controller (Dart Controls, USA). A schematic diagram of the system layout is shown in Fig. 1.

The volume displacement inside the hydraulic distributor (not shown in Fig. 1) was driven through the station hosting the aortic valve roots (Fig. 2). The ventricle hosted a total volume of $645 \mathrm{ml}$, channeled through the aortic root holder orifice of $25 \mathrm{~mm}$. The overall height of the station was $346 \mathrm{~mm}$, while the total ventricle height and major diameter were $138.5 \mathrm{~mm}$ and $90 \mathrm{~mm}$, respectively. The hydraulic distributor was isolated from the circulating working solution in the station by a silicon flange. The characteristic impedance was simulated using an adjustable clamp on the silicone tubing connecting the station to the compliance chamber, while the arterial resistance was located between the compliance chamber and the atrial reservoir. The reservoir hosted the $\mathrm{pH}$ electrode used to monitor proton release in the supersaturated solutions and a line ensuring the supply of water-saturated $\mathrm{N}_{2}$ vapor. A mechanical On-X, Cryolife valve simulated the mitral valve in the system.

All materials used to manufacture the circulatory loop in contact with the supersaturated solution were tested for calcification and proved inert to calcium phosphate formation.

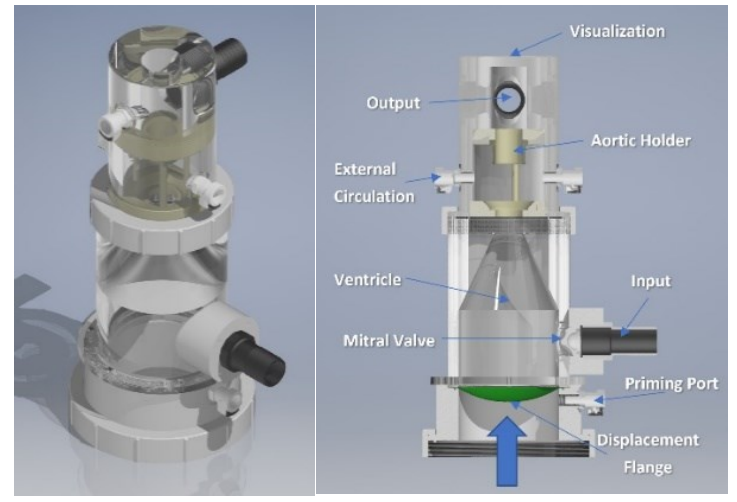

Fig. 2 Design of the dynamic model station

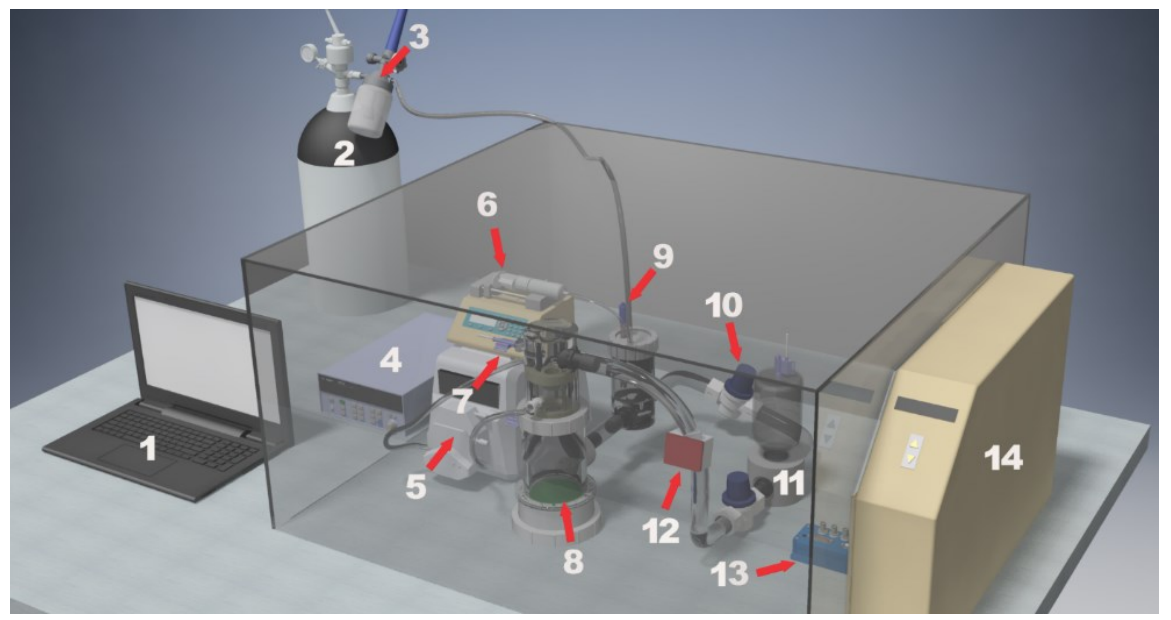

Fig. 1 Schematic diagram of the experimental dynamic calcification model. 1 - Computer, 2 - Nitrogen cylinder, 3 - Water saturator, 4 Pressure signal conditioner, 5 - Peristaltic pump, 6 - Syringe pump, 7 - Blood pressure sensor, 8 - Bioreactor station, 9 - pH probe, 10 Resistance, 11 - Compliance chamber, 12 - Ultrasonic sensor, 13 - pH signal conditioner, 14 - Heater 


\section{Glutaraldehyde fixation, decellularization, and sample preparation}

The heart valves used in this study were obtained from a local slaughterhouse. Valves were cleaned and fixed at the laboratory within $3 \mathrm{~h}$ past excision using $0.625 \%$ glutaraldehyde (Serva, Germany). Next, tissues were immersed in the fixing agent solution for 90 minutes under constant shaking and stored until use at $4{ }^{\circ} \mathrm{C}[26]$. The second batch of aortic valves was decellularized following previously published protocols [27, 28] Before decellularization, valves were disinfected as described in literature reports [29] using a solution containing polymyxin B $(0.2 \mathrm{mg} / \mathrm{ml}$, Sigma, USA $)$, vancomycin $(0.05 \mathrm{mg} / \mathrm{ml}$, Sigma, USA $)$ and gentamicin $(0.5 \mathrm{mg} / \mathrm{ml}$, Roth, Germany) in PBS for $1 \mathrm{~h}$ at $37^{\circ} \mathrm{C}$. Valves were decellularized using $0.5 \%$ Triton $\mathrm{X}-100$ and $0.5 \%$ SDS (Roth, Germany) for $24 \mathrm{~h}$ each, replacing the solutions every $12 \mathrm{~h}$. Washing was done in $12 \mathrm{~h}$ cycles, twice with distilled water and ten times with PBS. All steps were performed under agitation $(185 \pm 5 \mathrm{rpm})$ in an orbital shaking incubator at room temperature. The valves were stored in PBS containing $1 \%$ penicillin/streptomycin (Lonza Bioscience, USA) at $4{ }^{\circ} \mathrm{C}$ until use.

\section{E. Aortic pressure gradient and flow studies}

The pressure gradient was measured using two pressure sensors located before and after the aortic valve holder. The pressures at each point were acquired at a sampling rate of $1 \mathrm{kHz}$ for $36 \mathrm{~h}$. Measurements were done every $12 \mathrm{~h}$ to monitor the progress of the valvular stenosis. A total of four GAV specimens were used for this study. Flow measurements were done upstream of the aortic valve by an ultrasonic flow clamp (BioProTT BCT $3 / 4 \times 3 / 16 "$ A, emTec, Germany), shown in Fig. 1. The ultrasonic flow clamp was placed on the tubing and provided readings up to a frequency of $40 \mathrm{~Hz}$. The inner diameter of the silicone tubing corresponded to the orifice area of the aortic valve holder.

Flow conditions in the presented system were characterized by the calculation of the Reynolds and Womersley numbers. The Womersley number represents the relationship between inertial and viscous forces in a pulsatile environment, defined by (4) [30].

$$
\alpha=\frac{d}{2} \sqrt{\frac{\rho \omega}{\mu}}
$$

The fluid density is denoted by $\rho, \mu$ is the viscosity, $\omega$ the heart rate, and $d$ the diameter.

\section{F. X-ray images}

The acquisition of X-ray images was accomplished using a clinical mammographic unit (Hologic, Selenia Dimensions, USA) at the University Hospital of Patras. The X-ray tube consisted of a Tungsten anode with Rhodium filter ( $0.05 \mathrm{~mm}$ thickness), and the focal spot size was set at the small $(0.1 \mathrm{~mm})$ mode. The distance between the X-ray tube and the flat-panel detector was constant at $70 \mathrm{~cm}$.

\section{G. SEM-EDS microscopic analysis}

Specimens taken from the fibrosa and ventricularis sides of the leaflets from both GAV and DCV were dried and examined by SEM-EDS microscopy (Zeiss, LEO VP-35 equipped with a Bruker AXS microanalysis unit) to identify the deposited calcium phosphate solids.

\section{Results}

The dynamic model could successfully simulate the physiological human pressure waveforms, as shown in Fig. 3 [31]. The resistance of the circuit modified the upper and lower pressure limits, while the compliance affected the smoothness of the signal and attenuation of the dicrotic notch. Results obtained by ultrasonic flow measurements reported an average volumetric displacement of $1.8 \pm 0.5 \mathrm{~L} / \mathrm{min}$. The calculated average Reynolds number at the aortic position was 2,303, while the maximum computed value during the systolic phase was 20,992. Moreover, the Womersley number at the aortic location was 3.75. Observations of the leaflet motion confirmed the correct coaptation and closing of the prosthetic valve.

The histological assessment of DCV after hematoxylin/eosin staining is shown in Fig. 4. No cells were present in arterial walls and leaflets after decellularization. Collagenous fiber damage was not noticed, as seen in the histological sections, shown in Fig. 5.
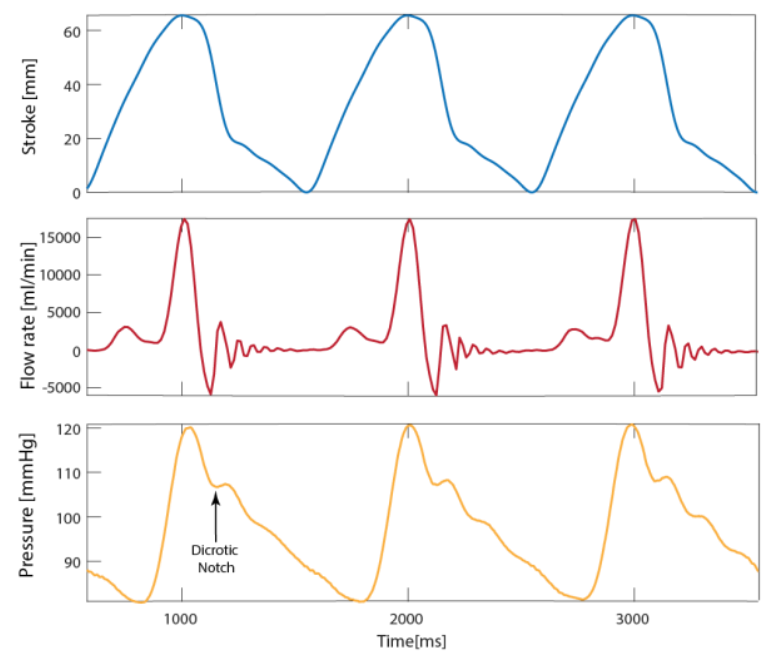

Fig. 3 Characteristic profiles of the linear actuator stroke, instantaneous flow, and pressure waveshapes as a function of time measured in the in vitro system 


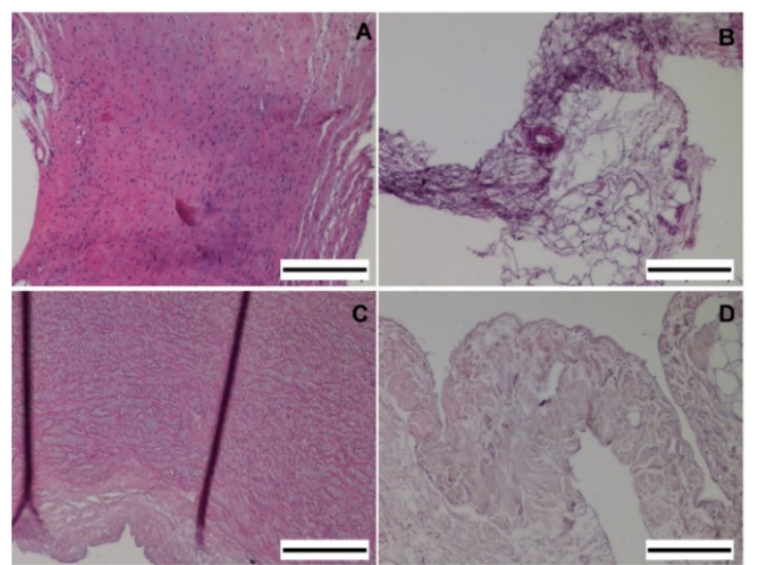

Fig. 4 H\&E staining of fresh (A, B) and DCV (C, D). Artery wall (A, C), leaflet (B, D). Scale bars indicate $200 \mu \mathrm{m}$

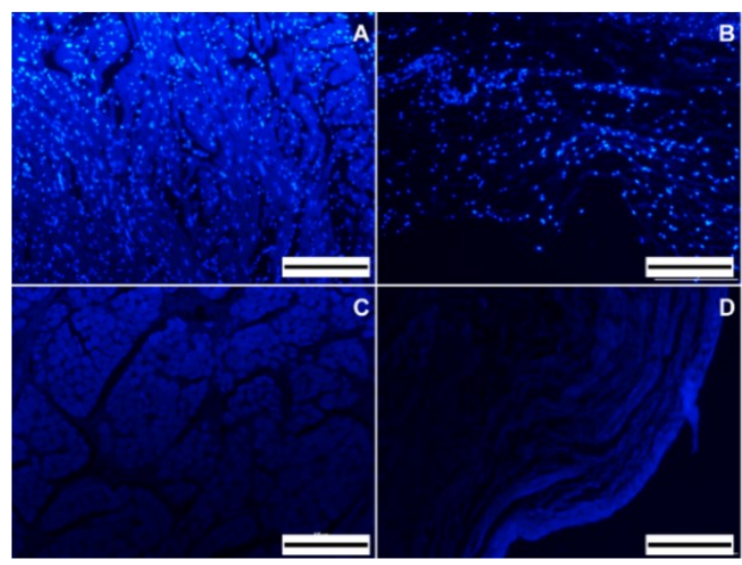

Fig. 5 DAPI staining of fresh (A, B) and DCV (C, D). Artery wall $(A, C)$, leaflet (B, D). Scale bars indicate $200 \mu \mathrm{m}$

In the experimental studies involving DCV and GAV specimens, the solution's temperature, $\mathrm{pH}$, and composition were kept constant. As seen in Fig. 6, the average $\mathrm{pH}$ drop of DCV $(\mathrm{n}=6)$ specimens was higher after $18 \mathrm{~h}$ in comparison with GAV specimens $(\mathrm{n}=5)$. The value of GAV $\mathrm{pH}$ drop tended to decrease over time, while DCV specimens exhibited $\mathrm{pH}$ drop tendency throughout the entire experiment. $\mathrm{NaOH}$ addition was almost identical during the first $8 \mathrm{~h}$ of the study with an increased addition for DCV $\left(1.21 \times 10^{-4} \pm\right.$ $\left.0.69 \times 10^{-4} \mathrm{~mol}\right)$ in comparison with GAV $\left(8.56 \times 10^{-5} \pm\right.$ $4.01 \times 10^{-5} \mathrm{~mol}$ ) after $18 \mathrm{~h}$. In Fig. 6 , the profiles of the volume of standard $\mathrm{NaOH}$ solution additions to maintain solution $\mathrm{pH}$ as a function of time, corresponding to the mineralization progress of the tissue, are shown. $\mathrm{pH}$ changes as small as $0.005 \mathrm{pH}$ units (ca. $0.1 \mathrm{mV}$ ) triggered the addition of $\mathrm{NaOH}$ solution. The model developed gave the possibility to perform tests even at very low supersaturations, in which bulk concentrations of calcium and phosphorus do not change to measurable extents (i.e., to within $1 \%$ ), yet the formation and growth of the minerals proceeds.

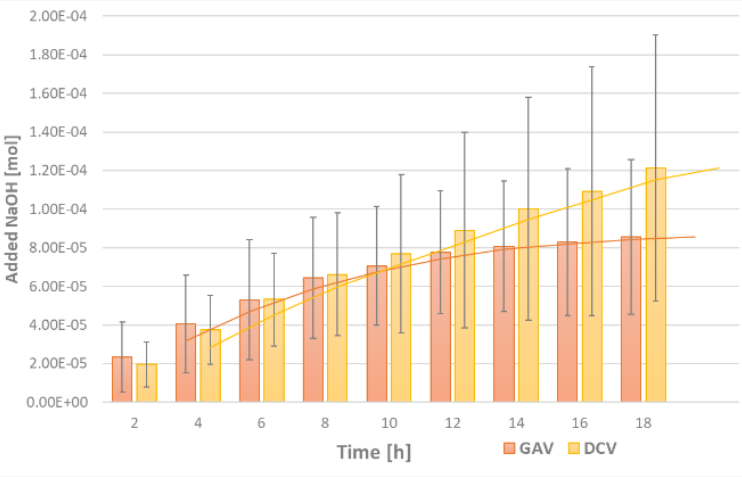

Fig. 6 Average $\mathrm{NaOH}$ added to compensate for the $\mathrm{pH}$ drop due to the mineralization of DCV $(n=6)$ and $\operatorname{GAV}(n=5)$ tissues. The difference between the mean values of the samples was statistically non-significant $(\mathrm{p}>0.05)$. Error bars indicate the standard deviation

Fig. 7 shows the pressure gradient measurements for GAV valves during a total time of $36 \mathrm{~h}$. The increase in the transvalvular pressure, measured directly before and after the GAV, indicated that the calcification solution affects the motility and pliability of the valve over time. The increased stenotic behavior was observable in less than $36 \mathrm{~h}$, in agreement with the accelerated calcification kinetics.

The assessment of the location and extent of calcification was done by X-Ray digital mammographic examination in three GAV specimens and compared with an untreated valve. As observed in Fig. 8, calcific deposits were selectively formed on the commissures and coaptation areas of the GAV leaflets.

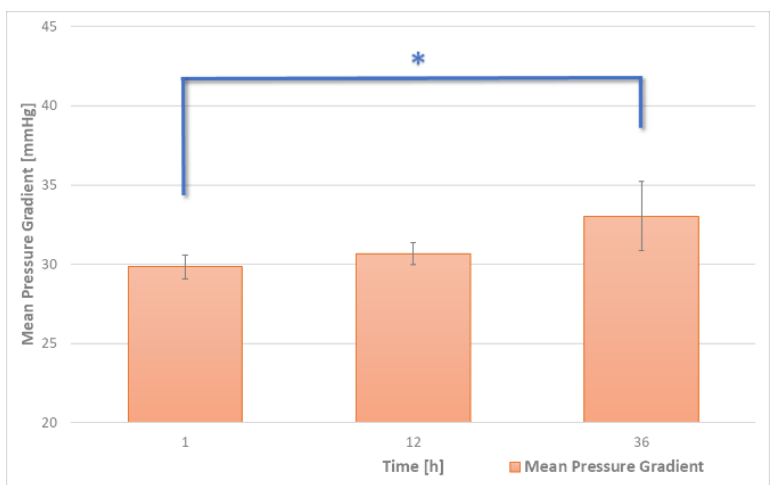

Fig. 7 Transvalvular mean pressure gradient results of GAV in a period of $36 \mathrm{~h}$. The differences between the measured means at $1 \mathrm{~h}$ and $36 \mathrm{~h}$ were statistically significant $\left(^{*}\right)(\mathrm{n}=4, \mathrm{p}<0.05)$. Error bars indicate the standard deviation 


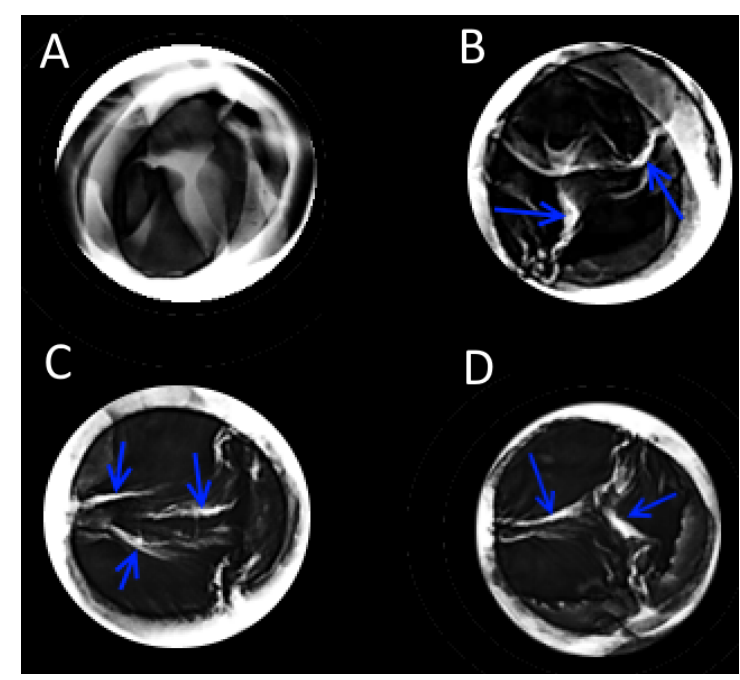

Fig. 8 X-Ray studies indicated that the GAV (B-D) suffered from calcification compared to an untreated valve root (A). The deposits concentrated on the edges of the valvular leaflets. External dense white areas correspond to the silicone tubing used as a scaffold during the imaging process

Additionally, SEM-EDS studies on GAV leaflets showed the presence of plate-like crystallites with sizes between 2-5 $\mu \mathrm{m}$ (Fig. 9), characteristic of OCP crystallites. EDS analysis showed that the crystallites consisted of calcium and phosphorous. Crystallites were not found in the form of suspended particles in the test fluid, which was filtered and carefully examined at the end of each experiment. The absence of crystals in the mineralization solution suggested that they adhered firmly to the substrate on which they formed selectively through the nucleation and crystal growth steps.

\section{Discussion}

In vitro calcification studies are fundamental sources of information and add to a better understanding of the mechanisms underlying tissue calcification. In vitro tests can be used as pre-screening tools for the design and fabrication of novel biomaterials. Earlier studies considered mechanical factors with respect to their respective role in tissue calcification [16, 18, 19]. Other investigations focused on the physicochemical factors of the calcification process [26,32]. However, none of the mentioned works investigated the calcification process under mechanical loading at fluid conditions of constant solution composition, in which the driving force, supersaturation, is maintained. Mechanical stress, in combination with full control of the solutions speciation, is a significant improvement in the simulation of physiological conditions in which tissue mineralization takes place.

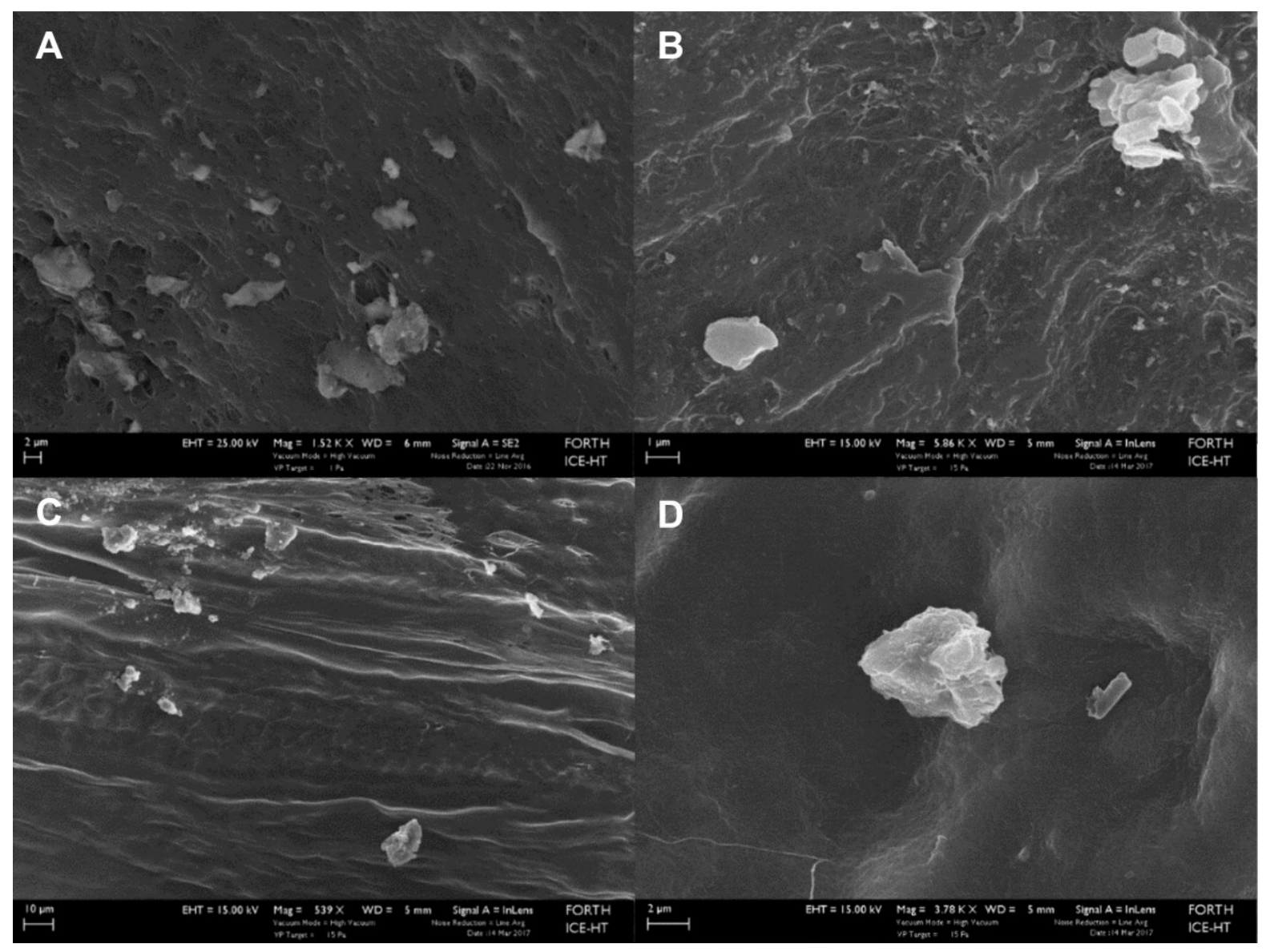

Fig. 9 SEM images showing crystal formations onto the leaflets of the GAVs (A, B) and DCVs (C, D). The left image corresponds to the fibrosa side, while the right one corresponds to the ventricularis side of the leaflets. The composition of the crystals was assessed through EDS 
In the present work, the solution chemistry role and the valvular mechanical load on the mineralization of tissues were investigated. The investigation was carried out at constant fluid chemical composition, simulating relevant in vivo conditions. The stability of the solution and the controlled chemical environment are the main characteristics that ensured crystal phase specificity, as observed in vivo. It should be noted that the supersaturated solutions used in the current work included inorganic species exclusively. This choice, which simplified the model system, is in full correspondence with the in vivo mineralizing medium (blood serum). The concentration of free calcium ions in blood plasma is rather low because of the sequestration of calcium ions by ionized proteins or amino acid molecules [33], resulting respectively low effective supersaturations with respect to calcium phosphate phases, which barely exceed values corresponding to HAP [11]. Nucleation on the studied specimens followed a controlled heterogeneous process, which was apparent from the composition and study of the test fluid samples. No visual crystallites were observed that could indicate uncontrolled spontaneous or secondary nucleation.

Characterization of the flow in the system is a relevant aspect of the crystallization study, as the type of flow regime in crystallizers has been shown to affect the microstructure of crystals [22]. The Reynolds and Womersley numbers calculation considered the viscosity of the aqueous media present in the system, which differed significantly from the blood (or other similar fluids) used to evaluate the fluid dynamics of artificial heart valves. Calculations were based on experimental data obtained during the validation of the system using a mechanical valve in the aortic position. Results obtained for the Reynolds number indicated that during systole, the flow could be characterized as turbulent. However, as seen in vivo, turbulent flow in the arteries is rare, given the reduced systolic ejection time and the unsteady nature of the flow [30]. Therefore, the calculation of the Reynolds number alone is not sufficient to characterize a pulsed flow system. Consequently, the Womersley number has been introduced to characterize pulsatile flow patterns, having a similar significance as the Reynolds number for unsteady flow conditions. The result obtained suggested that the inertial forces are predominant over the viscous forces present in the system. A more detailed study of the simulated flow characteristics is beyond the scope of the present work.

Structural alterations induced by calcification affect the biomechanical properties (elastic and collagen modulus) of the valves, resulting in a higher transvalvular pressure due to their stenotic behavior [34]. Decellularization of valvular scaffolds consists of the removal of the cellular components to enhance biocompatibility. Past decellularization, the treated valvular tissue is prone to cellular adhesion and proliferation, in an attempt to re-functionalize the cellular matrix in vivo or in vitro $[35,36]$. Literature data showed that only a few treatments delivered promising results in the short and medium-term [9]. Ineffective removal of cell debris and disruption of the extracellular matrix are among the main reasons why DCV are still under investigation. The presence of residual cells and cell debris following decellularization might explain the increase in the calcification rates shown by the DCV found by our system $[8,37,38]$. The increased exposure of collagen fibers following decellularization might also support these findings, as collagen fibers could serve as potential growth sites for calcium phosphate crystals [39, 40]. Stabilization and crosslinking of collagen fibers are possibly crucial for the calcification of the respective implants. Results shown by GAV studies suggested that the calcification of the respective specimens was possibly due to the presence of free aldehyde groups, in agreement with earlier reports [6]. Experiments with gradient pressure focused on GAV for a period of $36 \mathrm{~h}$. As seen in Fig. 7, the pressure gradient tended to increase during measurements. According to the European Society of Cardiology guidelines, mild aortic sclerosis corresponds to an aortic valve with a pressure gradient below $30 \mathrm{mmHg}$ compared to moderate $30-50 \mathrm{mmHg}$ and severe sclerosis $>50 \mathrm{mmHg}$ [41]. Results suggested that the reference for measurements of GAVs is a mild sclerotic situation. The higher initial pressure values may be explained by the testing methodology used, where a rigid polymeric holder was used to fix the aortic roots in the system. Further increase with time should be attributed to the stiffening of the valvular tissue by the deposition of calcium deposits. Due to the lack of a sterile controlled environment in the experimental model, more extended test periods, as well as other types of valvular scaffolds (DCV), were not included in the present study.

Surface anisotropy and inhomogeneity result in differences between the crystallization rates measured under the same conditions on different valve specimens. The specimens were standardized to a predetermined size to study the effect of surface anisotropy. Moreover, the standardization of samples ensured the preservation of the sinuses of Valsalva at the aortic root, necessary for the correct flow dynamics during the test procedure. Despite sample standardization, the natural variability of the tissue affected the target flow rates, mainly because of the diverted flow through the coronary openings.

SEM-EDS investigations of the surfaces of the valvular tissue of both GAV and DCV, shown in Fig. 9, confirmed the formation of calcium phosphate deposits, specifically OCP, in agreement with earlier studies [42]. X-Ray digital mammographic studies shown in Fig. 8 further corroborated the presence of calcific deposits on the valvular leaflets. The location of these deposits was in agreement with earlier reports $[16,19]$, while the topography of the sites of selective deposition of calcium phosphate crystallites is also in agreement with reported physiological observations 
[43]. Nevertheless, microscopical observations showed an increased presence of deposits on the fibrosa side rather than the ventricular side of the leaflets, in agreement with results obtained from the investigation of explanted calcified valves because of severe calcification [44]. These results are in agreement with earlier reports concerned with bovine pericardium mineralization [11].

The presented work provides a rapid and reliable prescreening platform for evaluating the calcification potential of different bioprosthetic valvular replacements. Results from the present work support the wide use of in vitro calcification models for the development of new tissue-engineered materials. In vitro systems, as the one presented, may directly impact the development costs of medical implants and the reduction of in vivo studies during the development stage. Nevertheless, because of the limitations of the in vitro models, in vivo studies remain the gold standard for the validation of medical devices.

The method presented in this work has not so far been used for comparisons with clinical findings.

\section{Conclusions}

The calcification process was modeled in vitro, focusing on the chemical environment and the mechanical load of the calcifying surfaces of heart valves. Results confirmed that the location and characteristics of the deposits achieved by our model occurred in a similar way as in vivo. The absence of biological factors, such as the immunological response, did not significantly affect the location of the deposits, predominately at areas of high stress, as confirmed by roentgenographic and SEM analytical investigations. Future studies related to this work shall focus on the evaluation of different test solutions emulating the physical properties of the blood serum and the impact on the mechanical load under different flow and pressure conditions. New synthetic biomaterial scaffolds are currently under preparation in our research group, which shall be assessed with respect to their calcification potential.

\section{Declarations}

\section{Funding}

This research was funded by the People Program (Marie Curie Actions) of the European Union's Seventh Framework FP7/2007-2013/ under REA grant agreement $n^{\circ} 317512$.

\section{Availability of data and material}

Available upon request.

\section{Code availability}

Available upon request.

\section{Conflicts of interest}

No benefits in any form have been or will be received from a commercial party related directly or indirectly to the subject of this manuscript.

\section{Animal studies}

No animal studies were carried out by the authors for this article.

\section{References}

1. Freeman R V, Otto CM (2005) Spectrum of Calcific Aortic Valve Disease: Pathogenesis, Disease Progression, and Treatment Strategies. Circulation 111:3316-26. https://doi.org/10.1161/CIRCULATIONAHA.104. 486738

2. Bowler MA, Merryman WD (2015) In vitro models of aortic valve calcification: solidifying a system. Cardiovasc Pathol 24:1-10. https://doi.org/10.1016/j.carpath.2014.08.003

3. Coffey S, Cairns BJ, Iung B (2016) The modern epidemiology of heart valve disease. Heart 102:7585. https://doi.org/10.1136/heartjnl-2014-307020

4. Dasi LP, Simon HA, Sucosky P, Yoganathan AP (2009) Fluid mechanics of artificial heart valves. Clin Exp Pharmacol Physiol 36:225-237. https://doi.org/10.1111/j.1440-1681.2008.05099.x

5. Butcher JT, Simmons CA, Warnock JN (2008) Mechanobiology of the aortic heart valve. J Heart Valve Dis 17:62-73

6. Simionescu DT (2004) Prevention of calcification in bioprosthetic heart valves: challenges and perspectives. Expert Opin Biol Ther 4:1971-85. https://doi.org/10.1517/14712598.4.12.1971

7. Tomazic BB, Brown WE, Schoen FJ (1994) Physicochemical properties of calcific deposits isolated from porcine bioprosthetic heart valves removed from patients following 2-13 years function. J Biomed Mater Res 28:527-527. https://doi.org/10.1002/jbm.820280416

8. Schoen FJ, Levy RJ (2005) Calcification of tissue heart valve substitutes: progress toward understanding and prevention. Ann Thorac Surg 79:1072-80.

https://doi.org/10.1016/j.athoracsur.2004.06.033

9. Vedepo MC, Detamore MS, Hopkins RA, Converse GL (2017) Recellularization of decellularized heart valves : Progress toward the tissue-engineered heart valve. https://doi.org/10.1177/2041731417726327

10. Wang L, Nancollas GH (2008) Calcium Orthophosphates: Crystallization and Dissolution. Chem Rev 108:4628-4669. https://doi.org/10.1021/cr0782574 
11. D'Alessandro CC, Komninou MA, Badria AF, et al (2020) Calcification assessment of bioprosthetic heart valve tissues using an improved in vitro model. IEEE Trans Biomed Eng 1-1. https://doi.org/10.1109/TBME.2019.2963043

12. Lerman DA, Prasad S, Alotti N (2015) Calcific Aortic Valve Disease: Molecular Mechanisms And Therapeutic Approaches. Eur Cardiol Rev 10:108. https://doi.org/10.15420/ecr.2015.10.2.108

13. LeGeros RZ (2001) Formation and transformation of calcium phosphates: Relevance to vascular calcification. Z Kardiol 90:116-124 https://doi.org/10.1007/s003920170032

14. Legeros RZ, Legeros JP (1984) Phosphate minerals in human tissues. Phosphate Miner 351-385. https://doi.org/10.1007/978-3-642-61736-2_12

15. Deiwick M, Glasmacher B, Baba H a, et al (1998) In vitro testing of bioprostheses: influence of mechanical stresses and lipids on calcification. Ann Thorac Surg 66:S206-S211. https://doi.org/10.1016/S0003-4975(98)01125-4

16. Bernacca GM, Fisher AC, Mackay TG, Wheatley DJ (1992) A dynamic in vitro method for studying bioprosthetic heart valve calcification. J Mater Sci Mater Med 3:293-298. https://doi.org/10.1007/BF00705296

17. Bernacca GM, Mackay TG, Wilkinson R, Wheatley DJ (1995) Calcification and fatigue failure in a polyurethane heart valve. Biomaterials 16:279-285. https://doi.org/10.1016/0142-9612(95)93255-C

18. Krings M, Kanellopoulou D, Koutsoukos PG, et al (2009) Development of a New Combined Test Setup for Accelerated Dynamic $\mathrm{pH}-$ Controlled in vitro Calcification of Porcine Heart Valves. Int J Artif Organs $32: 794-801$ https://doi.org/10.1177/039139880903201105

19. Barannyk O, Fraser R, Oshkai P (2017) A correlation between long-term in vitro dynamic calcification and abnormal flow patterns past bioprosthetic heart valves. J Biol Phys 43:279-296. https://doi.org/10.1007/s10867-017-9452-9

20. Rohnke M, Henss A (2016) Biomaterials-Potential nucleation agents in blood and possible implications. Biointerphases https://doi.org/10.1116/1.4954191

21. Weska RF, Aimoli CG, Nogueira GM, et al (2010) Natural and prosthetic heart valve calcification: Morphology and chemical composition characterization. Artif Organs 34:311-318. https://doi.org/10.1111/j.1525-1594.2009.00858.x

22. Tran T, Rousseau D (2016) Influence of shear on fat crystallization. Food Res Int 81:157-162. https://doi.org/10.1016/j.foodres.2015.12.022
23. Mura F, Zaccone A (2016) Effects of shear flow on phase nucleation and crystallization. Phys Rev E 93:042803.

https://doi.org/10.1103/PhysRevE.93.042803

24. Parkhurst DL, Appelo CAJ (2013) Description of input and examples for PHREEQC version 3-A computer program for speciation, batch-reaction, one-dimensional transport, and inverse geochemical calculations. In: Geological Survey Techniques and Methods. U.S. Geological Survey, p 497

25. Covington AK, Robinson RA (1975) References standards for the electrometric determination, with ion-selective electrodes, of potassium and calcium in blood serum. Anal Chim Acta 78:219-223. https://doi.org/10.1016/S0003-2670(01)84768-1

26. Mavrilas D, Kapolos J, Koutsoukos PG, Dougenis D (2004) Screening biomaterials with a new in vitro method for potential calcification: Porcine aortic valves and bovine pericardium. J Mater Sci Mater Med 15:699-704. https://doi.org/10.1023/B:JMSM.0000030212.5532 $0 . c 2$

27. Wang S, Oldenhof H, Goecke T, et al (2015) Sucrose Diffusion in Decellularized Heart Valves for FreezeDrying. Tissue Eng Part C Methods 21:922-931. https://doi.org/10.1089/ten.TEC.2014.0681

28. Theodoridis K, Müller J, Ramm R, et al (2016) Effects of combined cryopreservation and decellularization on the biomechanical, structural and biochemical properties of porcine pulmonary heart valves. Acta Biomater 43:71-77. https://doi.org/10.1016/j.actbio.2016.07.013

29. Granados M, Morticelli L, Andriopoulou S, et al (2017) Development and Characterization of a Porcine Mitral Valve Scaffold for Tissue Engineering. J Cardiovasc Transl Res 10:374-390. https://doi.org/10.1007/s12265-017-9747-z

30. Chandran KB, Rittgers SE, Yoganathan AP (2012) Biofluid Mechanics, 2nd ed. CRC Press, Boca Raton. https://doi.org/10.1201/b11709

31. Schultz MG, Davies JE, Hardikar A, et al (2014) Aortic Reservoir Pressure Corresponds to Cyclic Changes in Aortic Volume Physiological Validation in Humans. 1597-1603. https://doi.org/10.1161/ATVBAHA.114.303573/$/ \mathrm{DC} 1$

32. Kapolos J, Mavrilas D, Missirlis Y, Koutsoukos PG (1997) Model experimental system for investigation of heart valve calcificationin vitro. J Biomed Mater Res 38:183-190. https://doi.org/10.1002/(SICI)10974636(199723)38:3<183::AID-JBM1>3.0.CO;2-L

33. Warshaw AL, Lee K-H, Napier TW, et al (1985) Depression of serum calcium by increased plasma free fatty acids in the rat: A mechanism for hypocalcemia in acute pancreatitis. 
Gastroenterology

$89: 814-820$

https://doi.org/10.1016/0016-5085(85)90577-3

34. Oswal D, Korossis S, Mirsadraee S, et al (2007) Biomechanical characterization of decellularized and cross-linked bovine pericardium. J Heart Valve Dis 16:165-174

35. Baraki H, Tudorache I, Braun M, et al (2009) Orthotopic replacement of the aortic valve with decellularized allograft in a sheep model. Biomaterials 30:6240-6246. https://doi.org/10.1016/j.biomaterials.2009.07.068

36. Lichtenberg A, Tudorache I, Cebotari S, et al (2006) In vitro re-endothelialization of detergent decellularized heart valves under simulated physiological dynamic conditions. Biomaterials 27:4221-4229.

https://doi.org/10.1016/j.biomaterials.2006.03.047

37. Schenke-Layland K, Vasilevski O, Opitz F, et al (2003) Impact of decellularization of xenogeneic tissue on extracellular matrix integrity for tissue engineering of heart valves. J Struct Biol 143:201208. https://doi.org/10.1016/j.jsb.2003.08.002

38. Rieder E, Kasimir MT, Silberhumer G, et al (2004) Decellularization protocols of porcine heart valves differ importantly in efficiency of cell removal and susceptibility of the matrix to recellularization with human vascular cells. J Thorac Cardiovasc Surg 127:399-405

https://doi.org/10.1016/j.jtcvs.2003.06.017

39. Simon P, Grüner D, Worch H, et al (2018) First evidence of octacalcium phosphate@osteocalcin nanocomplex as skeletal bone component directing collagen triple-helix nanofibril mineralization. Sci Rep 8:1-17. https://doi.org/10.1038/s41598-01831983-5

40. Nudelman F, Lausch AJ, Sommerdijk NAJM, Sone ED (2013) In vitro models of collagen biomineralization. J Struct Biol 183:258-269. https://doi.org/10.1016/j.jsb.2013.04.003

41. Baumgartner H, Hung J, Bermejo J, et al (2009) Echocardiographic Assessment of Valve Stenosis: EAE/ASE Recommendations for Clinical Practice. J Am Soc Echocardiogr 22:1-23. https://doi.org/10.1016/j.echo.2008.11.029

42. Mikroulis D, Mavrilas D, Kapolos J, et al (2002) Physicochemical and microscopical study of calcific deposits from natural and bioprosthetic heart valves. Comparison and implications for mineralization mechanism. J Mater Sci Mater Med 13:885-889. https://doi.org/10.1023/A:1016556514203

43. Liu F, Coursey CA, Grahame-Clarke C, et al (2006) Aortic valve calcification as an incidental finding at CT of the elderly: Severity and location as predictors of aortic stenosis. Am J Roentgenol 186:342-349. https://doi.org/10.2214/AJR.04.1366
44. Hutson HN, Marohl T, Anderson M, et al (2016) Calcific aortic valve disease is associated with layerspecific alterations in collagen architecture. PLoS One 11:1-18. https://doi.org/10.1371/journal.pone.0163858 